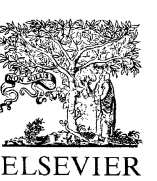

\title{
Early Cyclosporine A Withdrawal in Kidney Transplant Recipients Under a Sirolimus-Based Immunosuppressive Regimen: Pathological Study of Graft Biopsies at 1-Year Posttransplant
}

\author{
J.C. Ruiz, J.M. Campistol, A. Mota, D. Prats, A. Gutiérrez, A. Castro, J.R. Pinto, J. García, J.M. Morales, \\ J.M. Grinyo, and M. Arias
}

$\mathrm{T}$ HE ROLE of anticalcineurin agents, cyclosporine A (CyA) and tacrolimus (TRC), in the development of chronic allograft nephropathy (CAN) and subsequently in long-term graft survival seems to be of major importance owing to their nephrotoxic effect. ${ }^{1}$ Unfortunately, no successful alternatives are available to date. Sirolimus has shown a similar efficacy to CyA when used alone with respect to graft rejection rates and short-term graft survival, either in combination with steroids and azathioprine or with steroids and mofetil mycophenolate $(\mathrm{MMF}){ }^{2,3}$ With the objective of a low rejection rate and the minimization of CyA nephrotoxicity a multicenter, randomized, phase III trial at 3 years is currently ongoing in 57 centers in Europe, Canada, and Australia with a total of 525 patients enrolled. This trial compares two arms, a control arm (A) using CyA, fixed doses of sirolimus, and steroids, and a study arm (B) with CyA, concentration-controlled sirolimus, and steroids with suspension of CyA at 3 months' postransplant. Partial results of this study at 1 year have shown a low rejection rate in both arms with a significantly better graft function at 1 year in group B. ${ }^{4}$ Nevertheless, the pathological effects of CyA withdrawal have not yet been analyzed. In this report we present the results of graft biopsy evaluations at 1 year in a subgroup of patients.

\section{MATERIALS AND METHODS}

Graft biopsies at the moment of transplantation and at 1-year posttransplant were analyzed in the subgroup of patients included in Spain and Portugal. All patients with a functioning graft at 1 year and the two biopsies performed were considered (70 patients and 140 biopsies, corresponding to 35 patients in every group). Biopsies were evaluated locally according to the Banff' 95 classification and chronicity changes (ah, eg, ci, ct, and cv) were computed. ${ }^{5} \mathrm{~A}$ chronicity score (CS) was calculated as the sum of the last four items. These findings as well as renal function at 1 year were compared between the two groups. We considered the existence of progression of chronicity lesions when Banff encoding for every lesion was higher in the 1-year biopsy than in the transplant (basal) biopsy. When it was equal or lower it was considered as no progression. The CS was analyzed in the same way. It was considered the percentage of patients with progression of chronic- ity findings in every group (individual lesions and CS) and compared using the chi square test.

\section{RESULTS}

Among the 140 biopsies evaluated, 83 (59\%) were considered as adequate (more than 6 glomeruli and at least 1 artery), $31(22 \%)$ were considered as marginal, and the remaining $24(19 \%)$ were not satisfactory. One-year plasma creatinine level was $1.88 \mathrm{mg} / \mathrm{dL}$ in group A and $1.48 \mathrm{mg} / \mathrm{dL}$ in group $\mathrm{B}(P<.05)$. Progression of lesions was as follows (percentage of patients in group A and B, respectively): $c g$ $18.5 \%$ vs $19.2 \%(\mathrm{n}=53 ; P=\mathrm{NS}) ;$ ci $61.3 \%$ vs $56.7 \%(\mathrm{n}=$ $61 ; P=\mathrm{NS}) ;$ ct $51.6 \%$ vs $50 \%(\mathrm{n}=61 ; P=\mathrm{NS}) ; c v 32 \%$ vs $31.6 \%(\mathrm{n}=44 ; P=\mathrm{NS})$; ah $36.7 \%$ vs $32.3 \%(\mathrm{n}=61 ; P=$ NS). When the CS was considered it was observed progressing in $64 \%$ of cases in group A and in only $47.4 \%$ of cases in group $B(n=44)$, although this difference was not statistically significant.

\section{CONCLUSIONS}

Early CyA withdrawal in a regimen including sirolimus is followed by an improvement in graft function as well as in the pathological parameters that define chronic allograft nephropathy. This reduced severity of chronic lesions when CyA is eliminated might be attributed to a decreased chronic nephrotoxicity without an increase in the immunological response against the allograft. Nevertheless, the absence of a central pathological evaluation should serve to consider these results with caution.

From H. Valdecilla, Santander, Spain; H. Clinic i Provincial, Barcelona, Spain; H. Da Universidade De Coimbra, Coimbra, Portugal; H. Clinico, Madrid, Spain; H. Miguel Servet, Zaragoza, Spain; H. Geral de Santo Antonio, Porto, Portugal; H. Curry Cabral, Lisboa, Portugal; H. La Fe, Valencia, Spain; H. 12 de Octubre, Madrid, Spain; H. Bellvitge, Barcelona, Spain.

Address reprint requests to J.C. Ruiz, Hospital Universitario Valdecilla, Servicio de Nefrologia, 39008, Santander, Spain. 


\section{AKNOWLEDGMENTS}

We thank Dr Ana Sánchez (H. San Carlos, Madrid, Spain) for her inestimable collaboration in statistical analysis.

\section{REFERENCES}

1. Paul LC: Kidney Int 56:783, 1999
2. Groth CG, Bäckman L, Morales J-M, et al: Transplantation 67:1036, 1999

3. Kreis H, Cisterne JM, Land W, et al: Transplantation 69:1252, 2000

4. Johnson R, Oberbauer R, Kreis H, et al: XVIII International Congress of the Transplantation Society. Rome, 2000

5. Solez K, Benediktsson H, Cavallo T, et al: Transplant Proc 28:441, 1996 